\title{
Ablation of epidermal RXRa in cooperation with activated CDK4 and oncogenic NRAS generates spontaneous and acute neonatal UVB induced malignant metastatic melanomas
}

\author{
Sharmeen Chagani ${ }^{1,2}$, Rong Wang ${ }^{2,3}$, Evan L. Carpenter ${ }^{2}$, Christiane V. Löhr ${ }^{4}$, Gitali Ganguli-Indra 1,2,5
} and Arup K. Indra ${ }^{1,2,3,5,6^{*}}$

\begin{abstract}
Background: Understanding the underlying molecular mechanisms involved in the formation of cutaneous malignant melanoma is critical for improved diagnosis and treatment. Keratinocytic nuclear receptor Retinoid $X$ Receptor a (RXRa) has a protective role against melanomagenesis and is involved in the regulation of keratinocyte and melanocyte homeostasis subsequent acute ultraviolet (UV) irradiation.

Methods: We generated a trigenic mouse model system (RXRa ${ }^{e p-/-} \mid$ Tyr-NRAS ${ }^{\mathrm{Q} 61 K} \mid C D K 4^{R 24 C / R 24 C}$ ) harboring an epidermal knockout of Retinoid X Receptor a (RXRa $\left.{ }^{e p-1}\right)$, combined with oncogenic NRAS ${ }^{\mathrm{Q} 61 \mathrm{~K}}$ (constitutively active RAS) and activated CDK4 ${ }^{R 24 / R 24 C}$ (constitutively active CDK4). Those mice were subjected to a single neonatal dose of UVB treatment and the role of RXR a was evaluated by characterizing the molecular and cellular changes that took place in the untreated and UVB treated trigenic $R X R a^{e p-1-}$ mice compared to the control mice with functional RXRa.

Results: Here we report that the trigenic mice develops spontaneous melanoma and exposure to a single neonatal UVB treatment reduces the tumor latency in those mice compared to control mice with functional RXRa. Melanomas from the trigenic $R X R a^{e p-/-}$ mice are substantial in size, show increased proliferation, exhibit increased expression of malignant melanoma markers and exhibit enhanced vascularization. Altered expression of several biomarkers including increased expression of activated AKT, p21 and cyclin D1 and reduced expression of pro-apoptotic marker BAX was observed in the tumor adjacent normal (TAN) skin of acute ultraviolet B treated trigenic $R X R a^{e p-l-}$ mice. Interestingly, we observed a significant increase in p21 and Cyclin D1 in the TAN skin of un-irradiated trigenic $R X R a^{e p-/-}$ mice, suggesting that those changes might be consequences of loss of functional RXRa in the melanoma microenvironment. Loss of RXRa in the epidermal keratinocytes in combination with oncogenic $N R A S^{Q 61 K}$ and CDK ${ }^{R 24 C / R 24 C}$ mutations in trigenic mice led to significant melanoma invasion into the draining lymph nodes as compared to controls with functional RXRa.
\end{abstract}

Conclusions: Our study demonstrates the protective role of keratinocytic RxRa in (1) suppressing spontaneous and acute UVB-induced melanoma, and (2) preventing progression of the melanoma to malignancy in the presence of driver mutations like activated CDK4 ${ }^{R 24 C R 24 C}$ and oncogenic NRAS ${ }^{\mathrm{Q} 61 \mathrm{~K}}$.

Keywords: Keratinocytes, Melanocytes, Acute UVB, Retinoid-X-receptor a (RXRa), Malignant melanoma, Trigenic, Spontaneous melanoma, NRAS ${ }^{\mathrm{Q} 61 \mathrm{~K}}, \mathrm{CDK}^{\mathrm{R} 24 \mathrm{C} / \mathrm{R} 24 \mathrm{C}}$, Microenvironment

\footnotetext{
* Correspondence: Arup.Indra@oregonstate.edu

${ }^{1}$ Molecular and Cellular Biology Program, OSU, Corvallis 97331, OR, USA

${ }^{2}$ Department of Pharmaceutical Sciences, College of Pharmacy, OSU, Corvallis

97331, OR, USA

Full list of author information is available at the end of the article
} 


\section{Background}

Malignant melanoma is the deadliest form of skin cancer with approximately 76,000 new cases and an estimated 10,000 deaths in the US this year [1]. Although it arises in both the chronic and non-chronic UV damaged skin, epidemiological studies indicate an increased association with acute rather than chronic sun exposure [2]. Despite the fact that early detection and treatment of the tumor can lead to a high cure rate of patients, malignant melanoma has an unpredictable evolution due its high metastatic ability that is typically non-responsive to current therapies [3]. Melanoma originates in the pigment producing melanocytes, which protect the skin against harmful effects of UV irradiation of the sun. Transformation of melanocytes to cutaneous melanoma is a multistep process called melanomagenesis [4]. This involves formation of a benign nevus and radial proliferation of the melanocytes to the basement membrane in the skin known as radial growth phase followed by the vertical proliferation of the melanocytes called vertical growth phase into the dermis crossing the basement membrane. The tumor is considered invasive at this point and ultimately turns metastatic when the cells enter the bloodstream or lymphatic vessels from which they colonize to other tissues and organs [5]. Keratinocytes are predominantly present in the epidermis and support it through a constant cycle of proliferation and differentiation [6]. Keratinocytes protect the body from UV radiation through transfer of melanin from melanocytes [7], and promote melanocyte proliferation and homeostasis through secretion of paracrine factors $[8,9]$. Therefore, understanding the molecular mechanisms behind melanomagenesis is critical for elucidating novel pathways that can be co-opted to aid with diagnosis and treatment strategies.

Retinoid-X-Receptors (RXRs) subtypes $\alpha, \beta$, and $\gamma$ are members of the steroid hormone superfamily of nuclear receptors (NR), and play an important role in gene regulation mediating biological processes such as development, differentiation, and homeostasis [10]. RXRs function as ubiquitous DNA-binding transcription factors and heterodimerize with some 15 NR family members $[10,11]$, which results in synergistic induction of gene expression via multiple signaling pathways by interacting with several coactivators and corepressors [12]. Previously, we have shown that by deleting RXR $\alpha$ protein specifically in the epidermal keratinocytes via Cre-LoxP technology alters paracrine signals to the melanocytes enhancing melanomagenesis $[13,14]$. This deletion also increases melanocyte proliferation and leads to DNA damage repair that is flawed following acute UVB irradiation [10]. Loss of keratinocytic RXR $\alpha$ increases melanocytic tumor formation resulting from chemical carcinogenesis [14-16] and enhances the keratinocytic expression of mitogenic factors including Endothelin-1 (EDN1), Hepatocyte Growth Factor (HGF) and Stem Cell Factor (SCF) [13, 14, 17]. A progressive loss of keratinocytic RXR $\alpha$ protein was observed through analysis of human melanomas collected at different stages of disease progression starting from benign nevi to melanoma in situ and invasive and metastatic melanomas [14]. Through our previous studies we determined that when RXR $\alpha$ is knocked out in the epidermis in combination with an activated Cyclin-Dependent Kinase 4 (CDK4) homozygous-mutation (R24C|R24C), the bigenic mice exhibited an increase in melanomagenesis when treated with DMBA-TPA, suggesting abnormal RXR $\alpha$ signaling cooperates with a key oncogenic driver [14]. We have also shown that loss of keratinoctyic RXR $\alpha$ in combination with either oncogenic N-RAS $\left(N R A S^{Q 61 K}\right)$ or activating $C d k 4^{R 24 C / R 24 C}$ mutations in two separate bigenic models, enhances melanomagenesis through chronic UVB exposure [18].

In this study, we investigated the role of keratinocytic $\mathrm{RXR} \alpha$ in spontaneous and acute neonatal UVB induced melanoma formation as this is a more biologicallyrelevant model since malignant melanoma is epidemiologically associated with acute sun exposure [2]. The CDK4 pathway comprising of signaling components like p16 ${ }^{\text {INK4a }}$-cyclin D-CDK4/6-retinoblastoma is known to be altered in $90 \%$ of human melanomas [19], while 15$20 \%$ of melanoma cases show mutations in the NRAS gene [20]. We observed that Rxr $\alpha$ loss in the epidermal keratinocytes when combined with $C d k 4^{R 24 C / R 24 C}$ and $N R A S^{Q 61 K}$ mutations culminated in an enhanced number of spontaneous and acute UVB-induced melanocytic lesions relative to the control mice with functional RXR $\alpha$ $\left(R x r \alpha^{L 2 / L 2}\right)$. Melanomas from the spontaneous and UVB treated groups of trigenic $R x r \alpha^{e p-/-}$ mice were increasingly proliferative and exhibited an increased rate of malignant conversion and tumor vascularization, while apoptotic melanocytes were reduced. The draining lymph nodes of trigenic $R x r \alpha^{e p-/-}$ mice showed an increased number of melanoma cells invasion compared to the controls with functional $\mathrm{RXR} \alpha$. Additionally, the normal skin adjacent to the tumor from both groups of untreated and UVB-treated trigenic $R x \mathrm{r}^{\mathrm{ep}-/-}$ mice showed aberrant expression of several key markers of melanoma. In particular, we observed significant increase in the phosphorylated AKT, (active form of Protein Kinase B), p21 and Cyclin D1 and reduced expression of pro-apoptotic marker BAX in the UVB treated trigenic mice, while in the un-irradiated mice we observed a significant increase in expression of p21 and Cyclin D1. Altogether, our results indicate that ablation of keratinocytic RXR $\alpha$ in combination with driver mutations such as $N R A S^{\mathrm{Q} 61 K}$ and $C d k 4^{R 24 C / R 24 C}$, abets the formation of spontaneous melanomas that are malignant 
in nature and these effects are further exacerbated by a single neonatal UVB exposure.

\section{Methods \\ Mice}

Generation of $R x \mathrm{ra}^{e p-/-}$ [15], $C d k 4^{R 24 C / R 24 C}$ [21], and Tyr-NRAS ${ }^{\mathrm{Q} 61 K}$ [22] mice have been described previously. See Additional file 1: Figure S1 for breeding strategies for generation of the $R x r \alpha^{e p-/-}\left|T y r-N R A S^{\mathrm{Q} 61 K}\right|$ $C d k 4^{R 24 C / R 24 C}$ trigenic mice. All of the genotyping PCR primers used in this study are listed in Additional file 2: Table S2. Mice were accommodated in our approved University Animal Facility. These facilities have $12 \mathrm{~h}$ light cycles and food/water were provided ad libitum. Animal Care and Use Protocol (ACUP) granted all the institutional approvals for all experiments.

\section{UVB treatment of mice}

P2 mice which were age- and sex-matched $(n=12)$ were subjected to a single $800 \mathrm{~mJ} / \mathrm{cm} 2$ of UVB light dose from a UV box of four Philips TL-20 W/12RS UV-B [13], which activates the melanocytes to migrate from hair follicles into the extrafollicular epidermis and dermis [13] and leads to melanoma formation [23]. Upon weaning (21 days postnatal), mice were observed weekly for appearance of melanocytic tumors. By 6 months' post UVB, melanocytic tumors were analyzed and quantified, and biopsies of tumors and tumor adjacent normal (TAN) skin were recovered for further assays. The experiment was independently performed twice with at least six mice in each group of control and mutant mice.

\section{Histological analyses}

$5 \mu \mathrm{m}$ thick formalin-fixed paraffin (FFPE) sections were used for all histological analysis. Hematoxylin and eosin (H\&E) staining was performed as previously described [16].

\section{Immunohistochemistry}

All IHC studies, (fluorescent and chromogenic) were done on FFPE sections that were $5 \mu \mathrm{m}$ in thickness. Prior to staining, melanin pigment was bleached by treating slides with $5 \% \mathrm{H} 2 \mathrm{O} 2$ in $1 \mathrm{X}$ PBS for $60 \mathrm{~min}$ at $55^{\circ} \mathrm{C}$. All the antibodies used are detailed in Additional file 2: Table S1. For fluorescent TUNEL staining, the DeadEnd TUNEL System (Promega, no. TB235) was used as described [13]. A single section on the same slide without primary antibody was used as a negative control and all experiments were performed in triplicates. See Additional file 2: for a more in-depth protocol.

\section{Imaging and quantitation of histological experiments}

Leica DME light microscope equipped with its own software, version 3.3.1 was used to capture brightfield images. Whereas, a Zeiss AXIO Imager.Z1 was used to capture fluorescent images, which were analyzed with help of AxioVision 4.8 and Adobe Photoshop. Images from multiple random fields $(\sim 12-15)$ were captured from replicate mice in all groups, positive cell were counted and quantified using the ImageJ software (NIH). The slides were analyzed independently by two investigators in a double-blinded manner and significance was determined using a Student's two-tailed t-test as calculated by GraphPad Prism software.

\section{Immunoblotting analyses}

Standard protocols were used to perform all immunoblotting analyses (described in [13, 24]). After incubation with appropriate secondary antibody, signals were detected using immuno-chemiluminescent reagents (GE Healthcare, Piscataway, NJ). $\beta$-actin antibody (\#A300491, Bethyl) was used as a protein loading control. See Additional file 2: Supplementary Methods for detailed protocol. All the antibodies used for immuno-blotting has been listed in the Additional file 2: Table S1.

\section{Results}

\section{Ablation of epidermal Rxra expression in combination} with mutated Cdk4 and oncogenic NRAS mutations results in increased spontaneous and acute UVB-induced melanomagenesis

Previously we have mentioned that RXR $\alpha$ protein in the keratinocytes is involved in melanocyte homeostasis and melanomagenesis, in mouse models where Rxr is knocked out in the epidermal region $\left(R x r \alpha^{e p-/-}\right)[13,14$, 16]. Furthermore, loss of keratinocytic Rxra expression when combined with activated $C d k 4^{R 24 C / R 24 C}$ or oncogenic human NRAS (Tyr-NRAS ${ }^{\mathrm{Q} 61 K}$ ) after chronic UVBirradiation results in malignant melanoma formation [18]. Therefore, our hypothesis was that keratinocytic Rxr a ablation when combined with homozygous activated $C d k 4^{R 24 C / R 24 C}$ and heterozygous expression of human NRAS (Tyr-NRAS ${ }^{\mathrm{Q} 61 K}$ ) would result in enhanced formation of spontaneous malignant melanoma, which would be further aggravated/ accelerated by a single neonatal UVB-irradiation in the trigenic mouse model.

To that end, we have combined the $R x r \alpha^{e p-/-}$ mice, in which Rxr $\alpha$ was specifically deleted in epidermal keratinocytes, with oncogenic Neuroblastoma RAS Viral Oncogene Homolog (NRAS $\left.{ }^{\mathrm{Q} 61 K}\right)$ and activating $C d k 4^{R 24 C / R 24 C}$ to generate a trigenic mouse line by breeding together our $R x r \alpha^{e p-/-} \mid C d k 4^{R 24 C / R 24 C}$ and $R x r \alpha^{e p-1-} \mid$ Tyr-NRAS $S^{\mathrm{Q} 61 K}$ bigenic mouse lines. This will allow us to understand the contribution of epidermal $\mathrm{RXR} \alpha$ in melanoma formation together with aberrant signaling pathways such as MAPK and CDK4 and after a single neonatal UVB exposure. (see Materials and Methods, Additional file 1: Figure S1a). $R x r \alpha^{L 2 /}$ ${ }^{L 2}\left|C d k 4^{R 24 C / R 24 C}\right|$ Tyr-NRAS ${ }^{\mathrm{Q} 61 K}$ mice (floxed Rxra mice 
which contain LoxP sites that flank exon 4) were used as "controls" for wild-type Rxra. From here onwards, we will refer to the homozygous $C d k 4^{R 24 C / R 24 C}$ mutation as $C d k 4^{R 24 C}$. Groups of neonatal (P2) mice from control and trigenic mice were left with no UVB treatment and were monitored for spontaneous melanoma formation, while a second cohort of control and trigenic mice were exposed to a single dose of $800 \mathrm{~mJ} / \mathrm{cm}^{2} \mathrm{UVB}$ at P2 and monitored periodically for formation of melanocytic tumors (Additional file 1: Fig. S1b) [18]. Neonatal UVB dose stimulates migration of melanocytes into the epidermis and dermis and promotes melanomagenesis. [13, 23]. Melanocytic tumors in the UVB treated trigenic mice developed within 6-7 months of UVB treatment, while the spontaneous melanocytic lesions appeared approximately a year after birth. Here we have characterized and compared the melanocytic tumors in the $R x r \alpha^{e p-/-}\left|C d k 4^{R 24 C / R 24 C}\right| T y r-N R A S^{Q 61 K}$ mice induced by a single neonatal UVB exposure after 6 months of incubation, with the spontaneous melanocytic lesions that develop in the 12 month old $R x r \alpha^{e p-/-} \mid C d k 4^{R 24 C /}$ ${ }^{R 24 C} \mid$ Tyr-NRAS ${ }^{\mathrm{Q} 61 K}$ mice.

Phenotypically, overall skin of the control and trigenic mice was heavily pigmented throughout (Fig. 1a), which made it difficult to quantitate smaller melanocytic lesions. $R x r \alpha^{e p-1-}\left|C d k 4^{R 24 C / R 24 C}\right| T y r-N R A S^{\mathrm{Q} 61 K}$ mice with larger lesions were easier to quantitate, as they were raised at that size. Strikingly, UVB induced $R x r \alpha^{e p}$ ${ }^{-/}\left|C d k 4^{R 24 C / R 24 C}\right|$ Tyr-NRAS ${ }^{\text {Q61K }}$ mice developed significantly larger melanocytic tumors with some degree of ulceration compared to the untreated trigenic mice (Fig. 1a, b). To further characterize the bigenic "control" and trigenic mice, we performed hematoxylin and eosin (H\&E) staining on paraffin sections with thickness of $5 \mu \mathrm{m}$ on the dorsal skin from both genotypes. The melanocytic lesions were more densely pigmented (Fig. 1c, d), and were highly penetrant into the epidermal basal layer (Fig. 1c, d (inset)) and exhibited a significant increase in epidermal thickness in the skin of $R x r \alpha^{e p}$ ${ }^{-/}\left|C d k 4^{R 24 C / R 24 C}\right|$ Tyr-NRAS ${ }^{\text {Q61K }}$ mice compared to Rxro $^{L 2 / L 2}\left|C d k 4^{R 24 C / R 24 C}\right|$ Tyr-NRAS ${ }^{\mathrm{Q} 61 K}$ mice, although UVB seemed to exacerbate the effects (Fig. 1e, f). This phenotype is quite often seen in mice with an epidermal ablation of RXR $\alpha$, as the keratinocytes present in the basal layer are hyperproliferative [15]. We observed a significantly increase in both the radial growth phase (RGP) and vertical growth phase (VGP) of the melanocytic tumors in the dermis in the trigenic mice compared to the control in the untreated mice (Fig. 1g) while the UVB treated trigenic mice showed significantly heightened increase in the RGP and VGP relative to their control bigenic mice (Fig. 1h). Histopathological analyses confirmed that the melanocytic lesions from the no UVB treated trigenic mouse line are melanomas with hallmark features like round and/or spindle cell tumors and mild to moderate anisokaryosis, which is the variation in size of nuclei in excess of the normal range for a tissue. Meanwhile the lesions from the acute UVB treated trigenic mice are anaplastic melanomas with poor differentiation and moderate to marked anisokaryosis [5 times the normal nuclei size] (Additional file 1: Fig. S1c). Altogether, above results suggest that loss of epidermal Rxr $\alpha$ when combined with oncogenic NRAS and activated CDK4 results in melanomagenesis, which is further accelerated by a single neonatal UVB exposure reducing the tumor latency as shown in the Kaplan Meier curve (Additional file 3: Fig. S2a).

\section{Increased proliferation, malignant conversion, enhanced vascularization and reduced apoptosis in melanomas from trigenic mice lacking keratinocytic Rxra expression in the epidermis}

To further characterize the melanocytic tumors from the trigenic mice, we performed IHC analyses using specific antibodies for markers of proliferation, malignant conversion and vascularization. We aimed to elucidate the differences between melanomas from $R x r \alpha^{e p}$ ${ }^{-/}\left|C d k 4^{R 24 C / R 24 C}\right|$ Tyr-NRAS $S^{\mathrm{Q} 61 K}$ and their corresponding $R x r \alpha^{L 2 / L 2}$ controls from untreated mice at 12 months of age and 6 months after single neonatal UVB treatment as discussed above. In order to determine the proliferation index of the melanocytic tumors, we colabeled with antibodies for melanocyte-specific enzyme tyrosinase related protein 1 (TYRP1) and PCNA, the marker for proliferation (Fig. 2a, b) $[25,26]$. There was a significantly higher number of PCNA+/TYRP1+ colabeled proliferating melanocytes in the spontaneous melanocytic lesions from trigenic $R x r \alpha^{e p-1-}$ mice as compared to the corresponding control (See Fig. 2c). A further increase in proliferation was observed in the UVB treated trigenic mice compared to their respective controls (Fig. 2d). In order to determine the rate of malignant conversion of the melanocytic tumors, we performed IHC using a cocktail of antibodeies directed against melanoma antigens MART-1 and HMB45 [27]. The malignant melanoma antibody cocktail showed increased staining in the melanocytic tumors from the trigenic $R x r \alpha^{e p-/-}$ mice compared to their control mice in the untreated group (Fig. 2e). Furthermore, UVB treated groups displayed intense staining compared to the no UVB treated mice, which suggested that a larger population of malignant and aggressive cells were present in those melanomas (Fig. 2e, f). We then labeled for the endothelial cell-specific marker Cluster of Differentiation 31 (CD31) (Fig. 2g, h) [28]. Mice from the spontaneous (no UVB) and single UVB treated control groups exhibited a similar number of CD31+ cells compared to the trigenic $R x r \alpha^{e p-/-}$ mice. However, there was a presence 


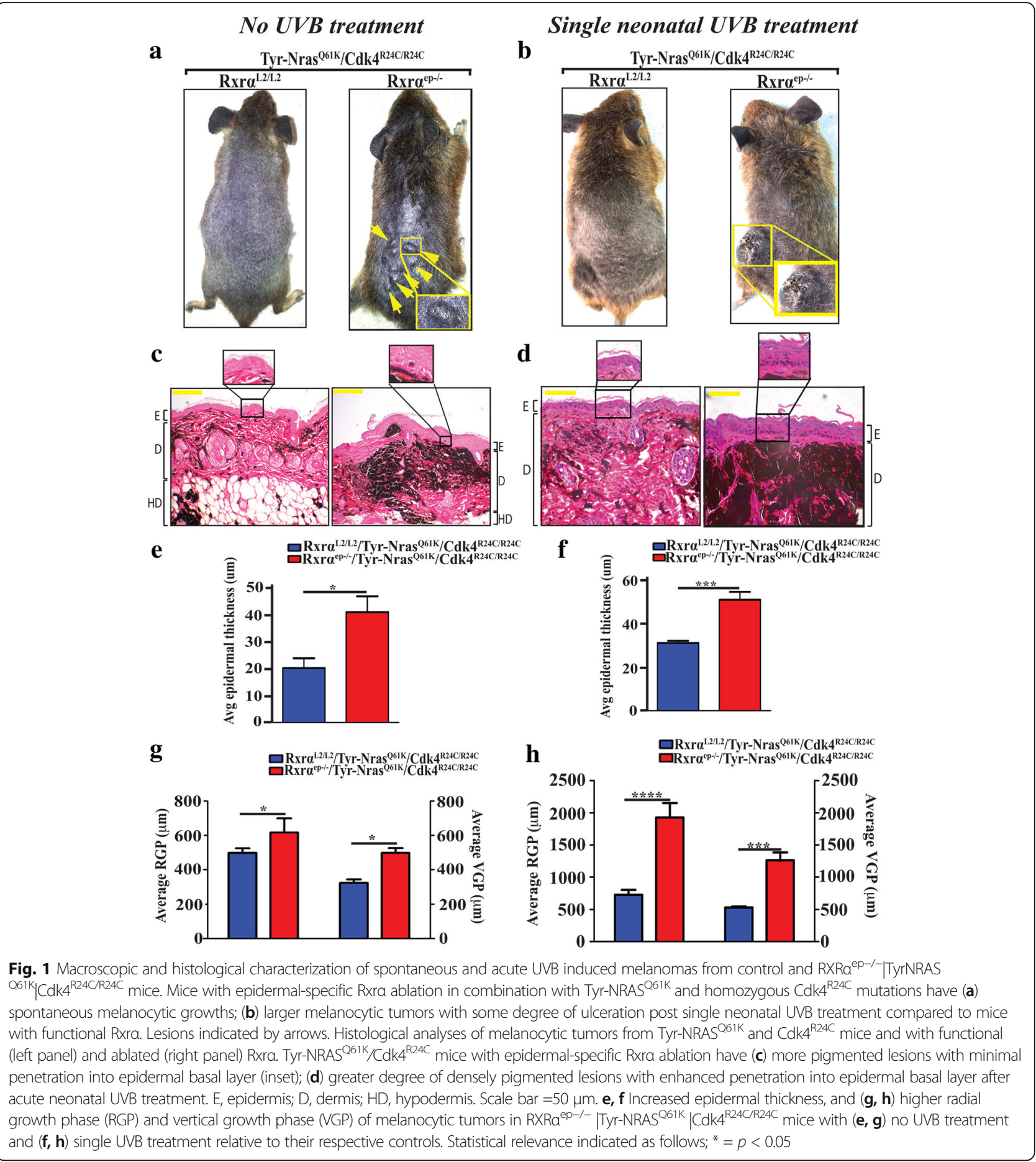

of complex CD31+ vasculature, which were larger and present comparatively at a higher incidence in the UVB treated trigenic $R x r \alpha^{e p-/-}$ mice (Fig. 2h, right panel). Altogether, above results indicate that abrogating Rxro expression in the epidermis in combination with activated CDK4 and N-RAS contributes to enhanced proliferation, malignant conversion, and vascularization of melanomas, and exposure to a single neonatal dose of UVB accelerates this process. To detect DNA strand breaks, terminal deoxynucleotidyl transferase-mediated dUTP nick end labeling (TUNEL) assay was used, which is often associated with apoptosis (Fig. 3a, b) [29]. The percentage of dermal TUNEL positive cells in trigenic mice was reduced compared to the controls both in the 


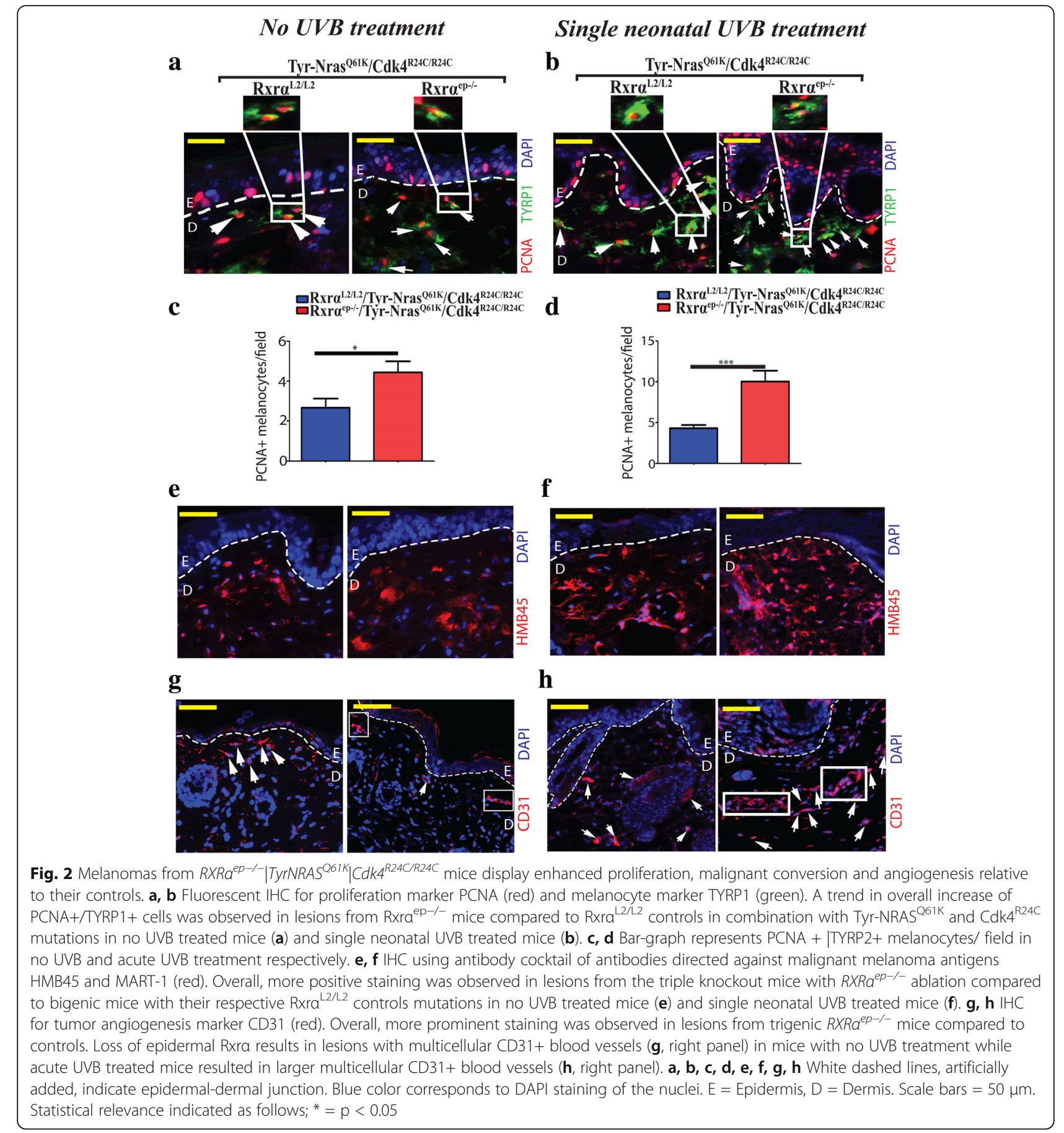

untreated and single UVB treated group (Fig. 3c, d) suggesting that keratinocytic RXR $\alpha$ plays a role in regulating apoptosis in the dermal melanomas.

Cutaneous melanomas in the $R \times \mathrm{xra}^{e p-/-}\left|\mathrm{Cdk} 4^{\mathrm{R} 24 \mathrm{C} / \mathrm{R} 24 C}\right|$ Tyr$N R A S^{061 K}$ trigenic mice metastasize to distal lymph nodes In order to understand what effects does loss of keratinocytic Rxr $\alpha$ have on metastasis of spontaneous and UVB induced melanomas, the axillary and inguinal draining lymph nodes (LNs) from $R x r \alpha^{e p-/-}\left|C d k 4^{R 24 C / R 24 C}\right| T y r-$ NRAS ${ }^{\mathrm{Q} 61 K}$ mice were analyzed for the presence of invasive melanocytes and compared them with lymph nodes from $R x r \alpha^{L 2 / L 2}\left|C d k 4^{R 24 C / R 24 C}\right|$ Tyr-NRAS ${ }^{\mathrm{Q} 61 K}$ (control) mice. Lymph nodes from the trigenic mice were enlarged compared to their respective control mice in both the UVB untreated (spontaneous) and treated groups, as there was more drainage in the mice where Rxr $\alpha$ was ablated in the epidermal keratinocytes (Fig. 4a, b). To further 


\section{No UVB treatment}

$\mathbf{a}$
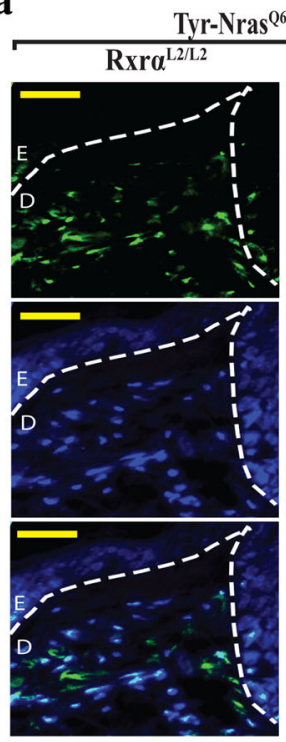

C
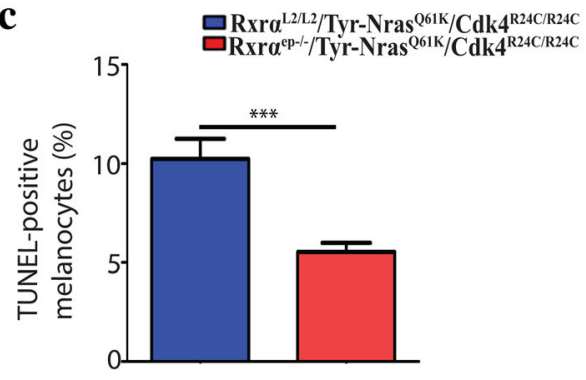

Single neonatal UVB treatment

b

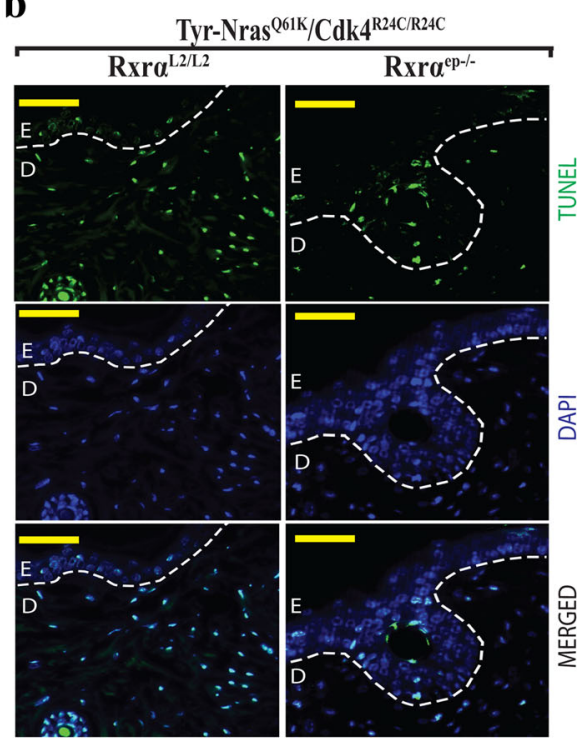

d
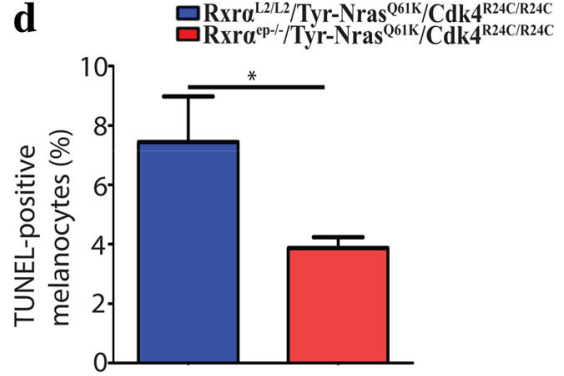

Fig. 3 Melanomas from trigenic $R X R a^{e p-1-} \mid$ TyrNRAS ${ }^{\mathrm{Q} 61 K} \mid C d k 4^{R 24 C / R 24 C}$ mice display reduced apoptosis relative to their controls with functional RXRa. a, b TUNEL assay to label apoptotic cells. Apoptotic cells are indicated by green staining (top panel), blue color corresponds to DAPI staining of the nuclei (middle panel) and merged TUNEL and DAPI cells (lower panel). Overall, reduced TUNEL positive staining was observed in lesions from trigenic Rxra ${ }^{\mathrm{ep}-1-}$ mice compared to their respective controls in mice with (a) no UVB treatment as well as the (b) acute UVB treated mice. $\mathbf{c}$, $\mathbf{d}$ Bar-graph represents TUNEL+ melanocytes/ field in no UVB and acute UVB treatment respectively

characterize the lymph nodes of the control and trigenic mice, we performed hematoxylin and eosin (H\&E) staining paraffin sections of the LNs from both the UVB untreated (spontaneous) and single UVB treatment groups (Fig. 4c, d). An increased number of pigment-containing cells in LNs from Rxr $^{e p-1-}\left|C d k 4^{R 24 C / R 24 C}\right|$ Tyr-NRAS $S^{\mathrm{Q} 61 K}$ mice was observed compared to the control mice in the group with spontaneous melanomas (Fig. 4c). Meanwhile, the trigenic mice in the single neonatal UVB treated group showed deep and highly pigmented regions compared to their corresponding controls (Fig. 4d). The presence of melanocytic cells in the LNs was analyzed by performing IHC staining for TYRP1 on LN sections from both mutant and control mice (Fig. 4e, f). We observed a significantly higher number of cells positive for TYRP1 in the trigenic group compared to the bigenic group with spontaneous melanomas (Fig. 4e), and a significant increase in TYRP1+ cells in LNs from the Rxra ${ }^{e p-/-}$ mice compared to their
$R x r \alpha^{L 2 / L 2}$ controls post acute neonatal UVB exposure (Fig. 4f). These results indicate that knocking out of epidermal Rxra expression in combination with oncogenic NRAS and activated CDK4 results in formation of spontaneous and UVB-induced melanomas with a hightened chance of metastasis of melanoma cells to the distal LNs.

\section{Altered melanoma signaling in tumor adjacent normal} (TAN) skin from spontaneous and acute UVB irradiated mice with loss of Rxra expression in the keratinocytes Since keratinocytic $R x \alpha^{e p-/-}$ mutant mice formed spontaneous and acute neonatal UVB-induced melanocytic lesions relative to control mice with functional $R X R \alpha$, our next aim was to understand if removal of keratinocytic Rxra also leads to phenotypic changes in the normal skin adjacent to the tumor that increases susceptibility to melanomas. To help characterize that, we performed immunoblotting analyses to determine the 


\section{No UVB treatment}

$\mathbf{a}$

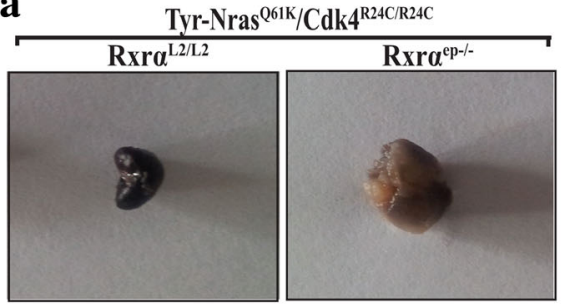

c

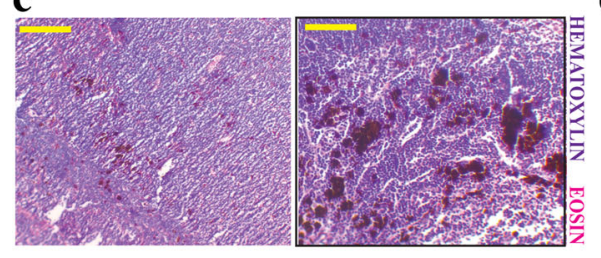

e

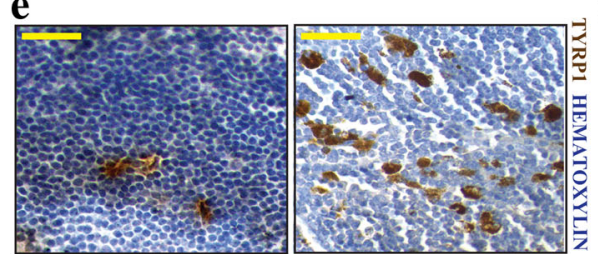

Single neonatal UVB treatment

b

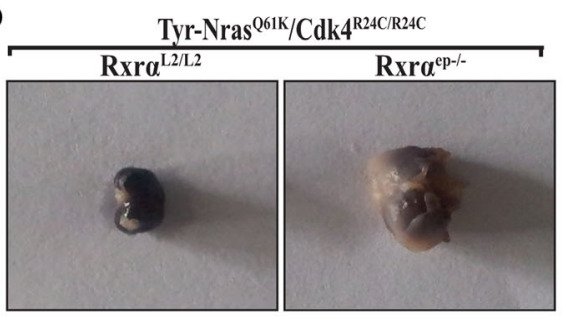

d

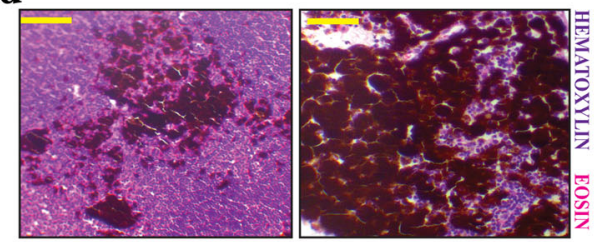

f

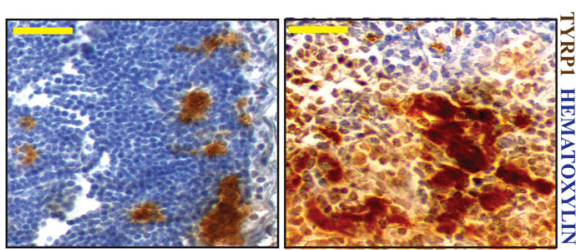

Fig. 4 Enhanced metastasis to draining lymph nodes in trigenic $R X R a^{e p-/-}\left|T y r-N R A S^{Q 61 K}\right| C d k 4^{R 24 C / R 24 C}$ mice relative to $R X r a^{L / L 2}$ control mice. a, b

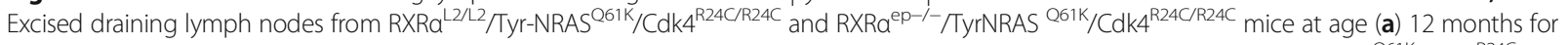
untreated mice and (b) 6 months for single UVB treated mice. (c, d) Histological analyses of draining lymph nodes from Tyr-NRAS ${ }^{\text {Q61K } / C d k 4 ~}{ }^{R 24 C}$ mice with functional and ablated Rxra in (c) no UVB treatment as well as the (d) acute UVB treated mice. e, $\mathbf{f}$ Chromogenic IHC for melanocyte-specific marker TYRP1 (brown). More positive staining overall is observed in RXRa ${ }^{\text {ep-l- } / \text { TyrNRAS }}$ Q61K/Cdk4 ${ }^{\text {R24C/R24C }}$ LNs as opposed to their relative RXRa ${ }^{\text {L2/L2 }}$ control LNs in both the UVB untreated and treated groups. Hematoxylin (purple) was used as a nuclear counterstain. Scale bar $=100 \mu \mathrm{m}$

changes in the expression of known key biomarkers of melanoma susceptibility on whole skin biopsies of tumor adjacent normal (TAN) skin from the spontaneous (no UVB) and single neonatal UVB-irradiated $R x r \alpha^{e p-/-}$ mutant mice and compared them to their controls. The TAN skin had no evidence of melanoma cells as observed from the histopathological analyses of both age matched nonUVB and UVB treated skin from bigenic control and trigenic mice (Additional file 3: Fig. S2b, c).

Our data indicates that ablation of keratinocytic Rxr $\alpha$ expression resulted in no significant increase in phosphorylation of AKT at Ser473 or total AKT levels in the no UVB treated $R x r \alpha^{e p-/-}$ mutants relative to their $R x r \alpha^{L 2 / L 2}$ controls (see Fig. 5a and Additional file 4: Fig. S3a). No appreciable difference in expression of its upstream regulator PTEN was also observed in the $R x r \alpha^{e p}$ ${ }^{-/}$mutants (Fig. 5a and Additional file 4: Fig. S3b). In neonatal UVB treated group, loss of epidermal Rxr expression resulted in a significant increase in expression of Ser473 phosphorylation of AKT with no change in the expression of total AKT and tumor suppressor PTEN (see Fig. 5b and Additional file 5: Fig. S4a, b). Immuno-blotting revealed that expression of p21 and cyclin D1 was significantly increased in $R x r \alpha^{e p-/-}$ mutant mice compared to their $R x r \alpha^{L 2 / L 2}$ control both in the UVB untreated and treated groups, while no change in the expression of p53 was observed (Fig. 5a, b and Additional file 4: Fig. S3c-e, Additional file 5: Fig. S4c-e). Pro-apoptotic protein BAX is moderately decreased in the $R x r^{e p-/-}$ mutant mice compared to its $R x r \alpha^{L 2 / L 2}$ control in the untreated group and a significant decrease in the treated groups (Fig. 5a, b and Additional file 4: Fig. S3f, Additional file 5: Fig. S4f). No significant changes in the expression of pro-Caspase 3 , another apoptosis related protein, was observed in the UVB untreated and treated TAN skin of $R x r \alpha^{e p-/-}$ mutant mice relative to the $R x r \alpha^{L 2 / L 2}$ mice (Figure $5 \mathrm{a}, \mathrm{b}$ and Additional file 4: Fig. S3 g, Additional file 5: Figure S4 g). Together, these results indicate that ablation of keratinocytic Rxr $\alpha$ expression consequences in an alteration of distinct important key signaling pathways involved in the melanoma microenvironment that elevates melanoma susceptibility.

\section{Discussion}

We have previously shown that keratinocytic RXR $\alpha$ has a role in acute UV-induced melanocyte proliferation [13], in chemically induced melanomagenesis [16] and in 


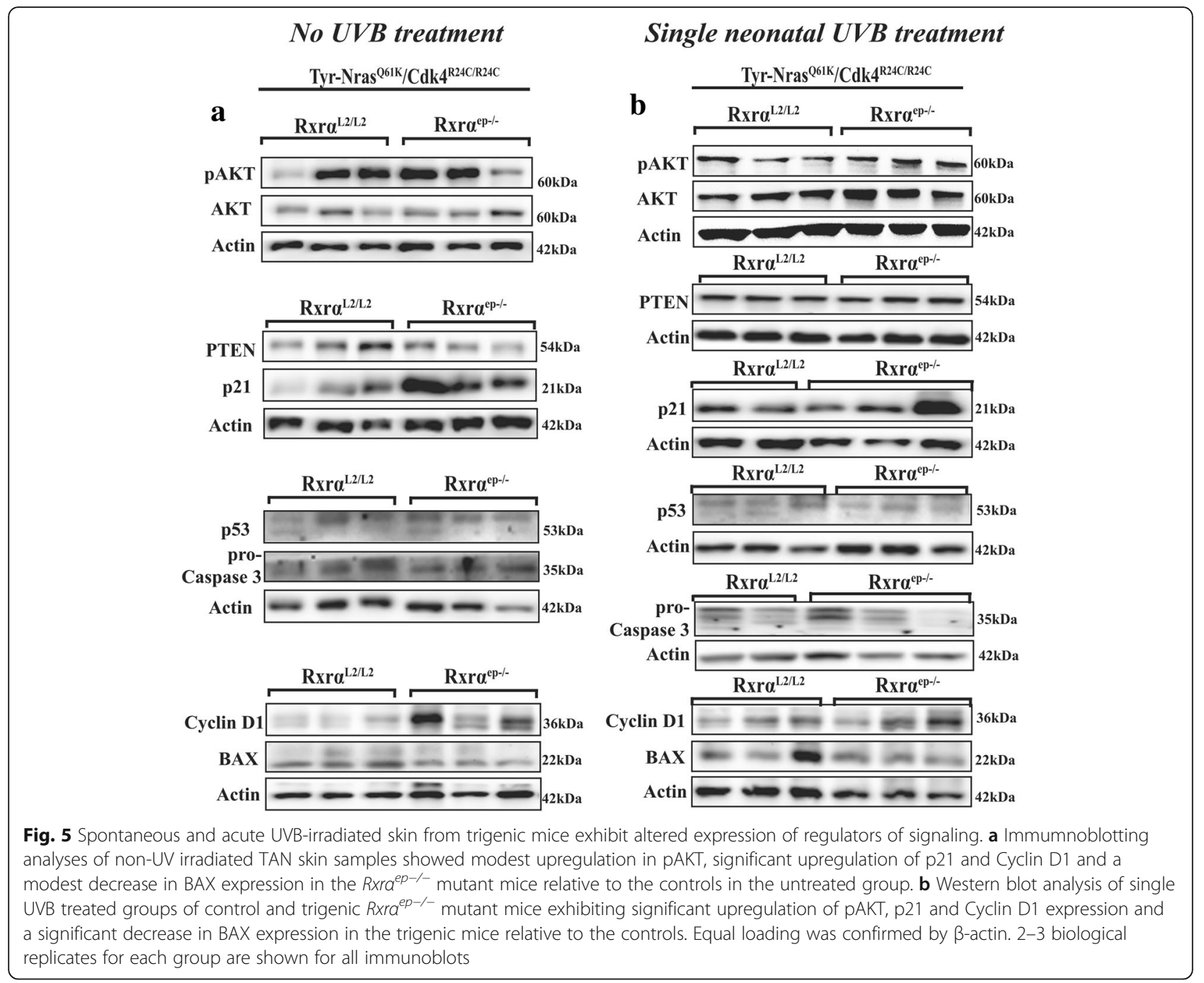

cutaneous melanoma formation when combined with mutant Cdk4 by chemical carcinogenesis [14]. We have also demonstrated that knocking out of epidermal RXR $\alpha$ in conjunction with oncogenic mutant $N R A S^{\mathrm{Q} 61 K}$ or activated $C d k 4^{R 24 C / R 24 C}$ promotes chronic UVB-induced melanoma formation [18]. As acute neonatal UV exposure is a major risk factor of cutaneous melanoma [2, 23, 30], we herein investigated the consequences of loss of epidermal RXR $\alpha$ in melanoma formation and determined its collaborative role with signaling pathways linked to melanoma driver mutations [NRAS (Q61K) and activated Cdk4 (R24C)] for the formation of spontaneous and acute UVB-induced melanomas. Our results suggests that keratinocytic RXR $\alpha$ has a protective role against aggressive melanoma formation induced spontaneously or after acute UVB irradiation. In comparison to the bigenic mice containing $R X R \alpha$ mutation and oncogenic mutant $N R A S^{\mathrm{Q} 61 K}$ or activated $C d k 4^{R 24 C /}$ ${ }^{R 24 C}$, which didn't show melanoma formation unless chronically irradiated with UVB for 30 weeks [18], the present trigenic mice $\left(R X R \alpha^{e p /-}\left|C d k 4^{R 24 C / R 24 C}\right| N R A S^{\mathrm{Q} 61 K}\right)$ develop spontaneous melanoma and in the presence of a single neonatal UVB treatment there is a significant reduction in tumor latency and rapid melanoma progression.

$R x r \alpha^{e p-/-}$ mice, in combination with $T y r-N R A S^{\mathrm{Q} 61 K}$ and homozygous $C d k 4^{R 24 C / R 24 C}$ mutations, developed increased number of spontaneous and acute UVBinduced melanocytic tumors that were also bigger in size with highly penetrating pigmented cells into the basal layer of the epidermis, compared to their corresponding $R x r \alpha^{L 2 / L 2}$ controls. Similar observations were previously made in lesions from our bigenic $R X R \alpha^{e p-/-} \mid$ Tyr$N R A S^{\mathrm{Q} 61 K}$ and $R X R \alpha^{e p-/-} \mid C d k 4^{R 24 C / R 24 C}$ mice when exposed to chronic UVB [18]. In the neonatal mice, when RXR $\alpha$ is ablated in the epidermis, there is an increase in skin hyperplasia, which is reflected by increased epidermal thickness due to proliferation and differentiation as observed in our mutant mice. A significant increase in RGP and VGP is observed when RXR $\alpha$ is lost in the epidermal keratinocytes in the trigenic mice where melanoma formation is seen spontaneously, and a single 
neonatal UVB exposure aggravates this effect. These observations have been reflected previously in our studies when $\mathrm{RXR} \alpha^{\mathrm{ep}-/-}$ mice were exposed to acute UVB [13] and when combined with mutant Cdk4 by chemical carcinogenesis [14]. Vertical growth phase is achieved when the nevus acquires both oncogenic and/or mitogenic characteristics, properties that enable cellular proliferation within a foreign matrix, an important step in tumor progression [31]. The increase in PCNA+/TYRP1+ cells within the $R X R \alpha^{e p-/}\left|T y r-N R A S^{\mathrm{Q} 61 K}\right| C d k 4^{R 24 C / R 24 C}$ skin as compared to the $R x r \alpha^{L 2 / L 2}$ control mice indicated the presence of a large volume of proliferating melanocytes in the mutant melanomas in absence or in presence of acute UVB. RXR $\alpha^{e p-/}\left|T y r-N R A S^{\mathrm{Q} 61 K}\right| \quad C d k 4^{R 24 C / R 24 C}$ melanocytic tumors displayed an increase in the number of cells that stained positive for melanoma antibody cocktail HMB45 and MART-1, which correlated well with the higher VGP in those mice, and a similar increase in CD31 staining implies that the larger melanocytic tumors formed in those mice would necessitate additional vascularization for nutritional support. Enhanced expression of melanoma antibody HMB45 cocktail has been correlated with melanocytic tumors and melanomas [27, 32, 33], while CD31 immuno-reactivity is closely linked to melanocytic tumor progression and the presence of its aggressive behavior [34]. In our previous study, both the two bigenic mouse lines $R x r \alpha^{e p-/-} \mid$ Tyr-NRAS ${ }^{\mathrm{Q} 61 K}$ and $R x \alpha^{e p-/-} \mid C d k 4^{R 24 C \mid R 24 C}$ [18] have increased expression of angiopoietin 1 (Angpt1), which contributes to formation of blood vessels. It is likely that increased angiogenesis in the UV irradiated trigenic mice could be, at least in part, due to increased Angpt1 expression. It remains to be determined whether RXR $\alpha$ directly regulate Angpt1 expression, or whether hypoxia/ altered HIF signaling in the melanoma microenvironment modulates secretion of angiogenic factors and contributes towards enhanced angiogenesis.

Failure to trigger apoptosis is a hallmark of cancer when low apoptotic indices in melanoma are observed, particularly in advanced stages [35]. Interestingly, a reduced percentage of TUNEL+ dermal melanocytes were detected in the mutant melanomas developed spontaneously or after acute UVB irradiation. Melanocytic lesions from DMBATPA treated $R x r \alpha^{e p-/-} \mid C d k 4 R 24 C$ mice [14] and in our chronic UVB exposed bigenic mice studies [18] were similarly proliferative, angiogenic and had malignant and metastatic characteristics, although reduction in apoptotic melanocytes in our trigenic $R x r \alpha^{e p-/-}$ mice is unique to the current study. Altogether, above data reiterates that formation of melanocytic tumors in the absence of keratinocytic RXR $\alpha$, and in the presence of oncogenic NRAS mutation and activated CDK4, have increased metastatic capabilities compared to the control mice with an accelerated effect in the acute UVB treated mice.
There was a higher degree of malignancy in melanomas from the trigenic $R x r \alpha^{e p-/-}$ mouse line, where we observed a higher number of TYRP1-expressing melanoma cells invading into draining lymph nodes in $R X R \alpha^{e p}$ ${ }^{-/} \mid$Tyr-NRAS $S^{\mathrm{Q} 61 K} \mid C d k 4^{R 24 C / R 24 C}$ mice with increased drainage seen in the UVB treated mice. In our DMBATPA treated $R x \alpha^{e p-/-} \mid C d k 4^{R 24 C / R 24 C}$ mice [14] and

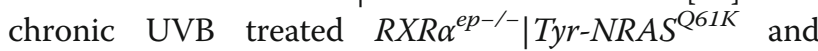
$R X R \alpha^{e p-/-} \mid C d k 4^{R 24 C / R 24 C}$ bigenic mice [18], we observed similar increase in proliferation, angiogenesis, and malignant/metastatic properties. However, no metastasis was observed in other internal organs like liver, lungs, brain and spleen. These observed results highlight a crucial role for RXR $\alpha$ in mediating melanocyte homeostasis, proliferation, angiogenesis and apoptosis and indicate that ablation of keratinocytic RXR $\alpha$ contributes to the progression of spontaneous and acute neonatal UVBinduced melanocytic tumors to malignant and metastatic tumors. These observations correlate well with our previous studies in human melanomas, which demonstrated that RXR $\alpha$ protein is progressively lost in the epidermal keratinocytes as tumors progress from benign nevi/lesions to aggressive melanomas [14].

We observed an increased expression of p21, a cyclin dependent kinase inhibitor and an upregulation of Cyclin D1 in the TAN skin from trigenic $R x r \alpha^{e p-/-}$, without appreciable difference in p53 expression. Although, we have previously observed a reduced expression of p53 in our chronic UVB exposed $R X R \alpha^{e p-/-} \mid$ Tyr-NRAS ${ }^{\mathrm{Q} 61 K}$ and $R X R \alpha^{e p-/-} \mid C d k 4^{R 24 C / R 24 C}$ bigenic mice skin [18] and P21 expression is known to be tightly regulated by p53 [36], p21 can be expressed without being induced by p53 via a p53 independent pathway $[37,38]$. At this point, it is uncertain if the lack of p53 downregulation is due to difference in the UV treatment regime (chronic vs acute) between the two studies. It also remains to be determined the presence of p53 somatic mutations in the spontaneous and acute UV induced melanomas, which may lead to loss of function of p53 protein. Progression of primary melanoma has been correlated with increased expression of Cyclin D1 $[39,40]$ and is upregulated due to inactivation of p53, although like p21, Cyclin D1 can be regulated independent of p53 expression [41].

PTEN functions as a tumor suppressor and the loss of functional PTEN results in AKT activation, suppression of apoptosis, and promotion of tumorigenesis [42]. PTEN and AKT normally share a homeostatic balance, and when PTEN is functionally suppressed results in increased phosphorylation of AKT [42] as observed previously in our chronic UVB exposed bigenic mice [18]. Although, we did not observe any loss of PTEN or an increase in activated, pAKT protein in $R x r \alpha^{e p-/-}$ TAN skin in the spontaneous melanocytic tumors, a significant increase in phosphorylated AKT at Ser 473 was noted in 
the acute UVB treated $R x r \alpha^{e p-/-}$ TAN skin. Different mechanisms of action may explain those findings in unirradiated skin, such as the inhibition of phosphorylation of AKT by PTEN may be impaired through its somatic mutation and inactivation, without alteration in protein expression as previously found in a number of malignancies including melanoma [43]. Alternatively, PI3K-independent activation of AKT such as ILK-1 associated phosphorylation of AKT at Ser 473 has been observed previously [44]. AKT activation independent of PI3K is also reported through glucagon-like peptide-1 (GLP-1) and glucose-dependent insulinotropic polypeptide (GIP) [45]. PI3K independent activation of AKT through a diverse group of tyrosine (Ack1/ TNK2, Src, PTK6) and serine/threonine (TBK1, IKBKE, DNAPKcs) kinases has been reported previously [46]. PTEN expression was unchanged in breast and ovarian cancers where the constitutively active AKT positive specimens show no alteration in PI3K or PTEN [47].

In addition, we observed a decrease in the expression of pro-apoptotic protein BAX in the UVB untreated $R x r \alpha^{e p-/-}$ TAN skin compared to the controls, which was also reduced in the mutant skin several weeks after exposure to a neonatal single UVB treatment. Similarly, expression of Pro-Caspase- 3 was moderately reduced in the acute UVB treated $R x x^{e p-/-}$ TAN skin, although we were unable to detect expression of cleaved Caspase-3. p53 mediated apoptosis usually involves upregulation of pro-apoptotic Bcl-2 members such as BAX and activation of Caspase-3 $[48,49]$, and BAX and Caspase 3 can also be activated independent of p53 activation [50,51]. Reduced expression of BAX and Pro-Caspase 3 in the mutant skin without significant changes in p53 expression could be a p53 independent event as reported earlier. Since the above results are generated from tumor adjacent skin, they firmly ascertain that loss of epidermal RXR $\alpha$ alone or together with acute neonatal UVB create a microenvironment in the skin that is prone to melanomagenesis mediated by driver mutations such as oncogenic NRAS and activated CDK4 mutations. Increased expression of $\mathrm{p} 21$ and Cyclin D1 that is observed

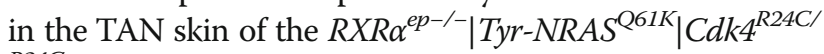
$R 24 C$ mice before and after acute UVB treatment, is likely due to the loss of RXR $\alpha$ in the epidermis, thereby contributing to changes in the expression of signaling molecules in the melanoma microenvironment. Acute UVB treatment induces additional alteration including a significant increase in PAKT and a significant decrease in Bax in the tumor microenvironment. It remains to be determined if there is any relationship between the NR signaling pathway and the $B R A F^{V 6 O 0 E}$ mutation, which is mutated in $>50 \%$ of human melanomas [52].

\section{Conclusions}

In summary, we demonstrate an important role of keratinocytic RXR $\alpha$ to (1) suppress the formation of spontaneous and acute UVB-induced melanomas, and (2) prevent their progression to malignancy in combination with activated $C D K 4^{R 24 C / R 24 C}$ and oncogenic $N R A S^{\mathrm{Q} 61 K}$. Altogether, $\mathrm{RXR} \alpha$ can potentially serve as a clinical prognostic marker and a target for mitigating UV-induced melanoma progression and metastasis in humans, although further studies are necessary in this direction for human relevance using in vitro co-culture techniques with human melanocytes and keratinocytes and in vivo using human xenograft models. Additional studies are also necessary to elucidate the molecular mechanisms underlying the non-cell autonomous role of keratinocyitc RXR $\alpha$ to drive melanomagenesis in the tumor microenvironment.

\section{Additional files}

Additional file 1: Figure S1. Breeding of mouse lines and UV scheme used in this study. (a) Breeding crossings used. K14-Cre ${ }^{\text {tg/O }} \mid$ Rxra ${ }^{L 2 / L 2}$ is also known as Rxra ${ }^{\mathrm{ep}-/-}$. (b) Scheme for single neonatal UVB treatment of mice. (c) H\&E stained section showing poorly differentiated melanoma with abnormally large nuclei compared to the normal range (inset). (TIFF 1999 kb)

Additional file 2: Table S1. Antibodies used for immuno-histochemical staining and immuno-blotting with details including the host, detection for-, the source, application and the dilution used. Table S2. PCR primers used for genotyping of mouse lines with the forward and reverse primers for K14-Cre, RXRa and CDK4, their sequences and the expected band sizes. Additional Methods. (DOCX $19 \mathrm{~kb}$ )

Additional file 3: Figure S2. Tumor latency of the mouse models and histological analyses of TAN skin from un-treated and acute-UVB treated mice. (a) Kaplan-meier curve showing tumor latency in the untreated and UVB treated mice. Reduced tumor latency seen in UVB treated mutant mice compared to UVB untreated mutants. Ticks indicate when a mouse in that group was censored (removed from the study). (b, c) H\&E staining of TAN skin of non-UVB treated skin and TAN skin from acute-UVB treated mice. In all groups, TAN skin has similar morphology in both the non-UVB treated skin and single neonatal UVB treated skin, except for increased epidermal thickening; and deeper dermal pigmentation seen in the RXRa ${ }^{\text {ep-l- }}$ mice. $\mathrm{E}=$ Epidermis, $\mathrm{D}=$ Dermis, scale bar $=100 \mu \mathrm{m}$. (TIFF $2257 \mathrm{~kb}$ )

Additional file 4: Figure S3. Changes in the expression of different cellular proteins from the TAN skin in the UVB untreated mice.

Quantification of western blot. $(a, b)$ Graphs showing expression of pAKT normalized with AKT and PTEN normalized with actin, no significant change. (c, d, e) Graphs showing expression of p21, cyclin D1 and p53 normalized against actin, with significant increase in p21 $(p<0.05)$ and cyclin D1 $(p<0.01)$ and no significant change in p53. (f, g) Graphs showing expression of bax and pro-caspase 3 normalized against actin, with no significant changes in both bax and pro-caspase 3. (TIFF $273 \mathrm{~kb}$ )

Additional file 5: Figure S4. Changes in the expression of different cellular proteins from the TAN skin in the UVB treated mice. Quantification of western blot. ( $a, b)$ Graphs showing expression of significant increase in pAKT normalized with AKT $(p<0.05)$ and PTEN normalized with actin with no significant change. $(c, d, e)$ Graphs showing expression of p21, cyclin D1 and p53 normalized against actin, with significant increase in p21 $(p<0.01)$ and cyclin D1 $(p<0.05)$ and no significant change in p53. ( $f, g)$ Graphs showing expression of bax and pro-caspase 3 normalized against actin, with significant decrease in bax $(p<0.05)$ and no significant changes in pro-caspase 3. (TIFF 275 kb)
Abbreviations

LN: Lymph node; NR: Nuclear receptor; TAN: Tumor adjacent normal; Tyr: Tyrosinase; TYRP1: Tyrosinase-related protein 1; UVB: Ultraviolet B; UVR: Ultraviolet radiation 


\section{Acknowledgements}

We thank all members of the Indra lab and the OSU College of Pharmacy; specifically, Drs. Mark Zabriskie, Gary Delander and Theresa Filtz for their continuous support and encouragement. We would also like to thank Dr. Friedrich Beermann, École Polytechnique Fédérale De Lausanne, Switzerland for providing the Tyr-Nras ${ }^{\mathrm{Q} / K}$ mice and Dr. Mariano Barbacid, Centro Nacional de Investigaciones Oncologicas (CNIO), Madrid, Spain for the CDK4 ${ }^{R 24 / R 24 C}$ mice.

\section{Funding}

Research reported in this publication was supported by NIEHS of the $\mathrm{NIH}$ under award numbers ES016629-01A1. The funding body has no role in the design of the study and collection, analysis, and interpretation of data and in writing the manuscript.

\section{Availability of data and materials}

The datasets during and/or analyzed during the current study available from the corresponding author on reasonable request after publication and after signing off the relevant Material Transfer Agreement.

\section{Authors' contributions}

Conceived and designed the experiments: SC, AKI, GGI. Performed the experiments: SC, RW. Analyzed the data: SC, AKI, CVL, EC, RW. Drafted the manuscript: SC, AKI. Revised the manuscript critically for important intellectual content: SC, AKI, GGl, EC. All authors have read and approved the manuscript.

\section{Ethics approval}

The current study was approved by the Institutional Animal Care and Use Committee (IACUC) at Oregon State University and all the animal studies are in compliance with the institutional regulations concerning the care and use of animals in the most ethical and humane way.

\section{Consent for publication}

Not applicable.

\section{Competing interests}

The authors declare that they have no competing interests.

\section{Publisher's Note}

Springer Nature remains neutral with regard to jurisdictional claims in published maps and institutional affiliations.

\section{Author details}

'Molecular and Cellular Biology Program, OSU, Corvallis 97331, OR, USA. ${ }^{2}$ Department of Pharmaceutical Sciences, College of Pharmacy, OSU, Corvallis 97331, OR, USA. ${ }^{3}$ Linus Pauling Institute, OSU, Corvallis, OR, USA. ${ }^{4}$ College of Veterinary Medicine, Oregon State University, Corvallis, Oregon 97331, USA. ${ }^{5}$ Knight Cancer Institute, Oregon Health \& Science University (OHSU), Portland 97239, OR, USA. ${ }^{6}$ Department of Dermatology, OHSU, Portland 97239, OR, USA

\section{Received: 14 September 2016 Accepted: 30 October 2017}

\section{Published online: 09 November 2017}

\section{References}

1. Am Cancer Soc Cancer Facts \& Figures 2016. In. Atlanta: American Cancer Society; 2016.

2. Gandini S, Sera F, Cattaruzza MS, Pasquini P, Picconi O, Boyle P, Melchi CF. Meta-analysis of risk factors for cutaneous melanoma: II. Sun exposure. Eur J Cancer. 2005;41(1):45-60

3. Orzan OA, Sandru A, Jecan CR. Controversies in the diagnosis and treatment of early cutaneous melanoma. J Medicine Life. 2015;8(2):132-41.

4. Meier F, Nesbit M, Hsu MY, Martin B, Van Belle P, Elder DE, SchaumburgLever G, Garbe C, Walz TM, Donatien P, et al. Human melanoma progression in skin reconstructs : biological significance of bFGF. Am J Pathol. 2000; 156(1):193-200

5. Larue L, Beermann F. Cutaneous melanoma in genetically modified animals. Pigment cell research / sponsored by the European Society for Pigment Cell Research and the International Pigment Cell Society. 2007;20(6):485-97.

6. Cook PW, Pittelkow MR, Shipley GD. Growth factor-independen proliferation of normal human neonatal keratinocytes: production of autocrine- and paracrine-acting mitogenic factors. J Cell Physiol. 1991;146(2): 277-89.

7. Brenner M, Hearing VJ. The protective role of melanin against UV damage in human skin. Photochem Photobiol. 2008:84(3):539-49.

8. Hyter S, Indra AK. Nuclear hormone receptor functions in keratinocyte and melanocyte homeostasis, epidermal carcinogenesis and melanomagenesis. FEBS Lett. 2013;587(6):529-41.

9. Scott MC, Suzuki I, Abdel-Malek ZA. Regulation of the human melanocortin 1 receptor expression in epidermal melanocytes by paracrine and endocrine factors and by ultraviolet radiation. Pigment cell research / sponsored by the Eur Society Pigment Cell Research and the Int Pigment Cell Society. 2002;15(6):433-9.

10. Chambon P. A decade of molecular biology of retinoic acid receptors FASEB journal : official publication of the Federation of American Societies for Experimental Biology. 1996:10(9):940-54.

11. Leid M, Kastner $P$, Chambon P. Multiplicity generates diversity in the retinoic acid signalling pathways. Trends Biochem Sci. 1992;17(10):427-33.

12. Altucci L, Gronemeyer $\mathrm{H}$. Nuclear receptors in cell life and death. Trends Endocrinol Metab. 2001;12(10):460-8.

13. Wang Z, Coleman DJ, Bajaj G, Liang X, Ganguli-Indra G, Indra AK. RXRalpha ablation in epidermal keratinocytes enhances UVR-induced DNA damage, apoptosis, and proliferation of keratinocytes and melanocytes. J Investigative Dermatology. 2011;131(1):177-87.

14. Hyter S, Bajaj G, Liang X, Barbacid M, Ganguli-Indra G, Indra AK. Loss of nuclear receptor RXRalpha in epidermal keratinocytes promotes the formation of Cdk4-activated invasive melanomas. Pigment cell \& melanoma research. 2010;23(5):635-48.

15. Li M, Chiba H, Warot X, Messaddeq N, Gerard C, Chambon P, Metzger D. RXR-alpha ablation in skin keratinocytes results in alopecia and epidermal alterations. Development. 2001;128(5):675-88.

16. Indra AK, Castaneda E, Antal MC, Jiang M, Messaddeq N, Meng X, Loehr CV, Gariglio P, Kato S, Wahli W, et al. Malignant transformation of DMBA/TPAinduced papillomas and nevi in the skin of mice selectively lacking retinoidX-receptor alpha in epidermal keratinocytes. J Investigative Dermatology. 2007;127(5):1250-60

17. Hyter S, Coleman DJ, Ganguli-Indra G, Merrill GF, Ma S, Yanagisawa M, Indra AK. Endothelin-1 is a transcriptional target of p53 in epidermal keratinocytes and regulates ultraviolet-induced melanocyte homeostasis. Pigment cell \& melanoma research. 2013;26(2):247-58.

18. Coleman DJ, Chagani S, Hyter S, Sherman AM, Lohr CV, Liang X, GanguliIndra G, Indra AK. Loss of keratinocytic RXRalpha combined with activated CDK4 or oncogenic NRAS generates UVB-induced melanomas via loss of p53 and PTEN in the tumor microenvironment. Molecular Cancer Res : MCR. 2015;13(1):186-96.

19. Sheppard KE, McArthur GA. The cell-cycle regulator CDK4: an emerging therapeutic target in melanoma. Clinical cancer research : an official journal of the American Association for Cancer Research. 2013;19(19):5320-8.

20. Kwong LN, Costello JC, Liu H, Jiang S, Helms TL, Langsdorf AE, Jakubosky D, Genovese G, Muller FL, Jeong JH, et al. Oncogenic NRAS signaling differentially regulates survival and proliferation in melanoma. Nat Med. 2012:18(10):1503-10.

21. Rane SG, Dubus P, Mettus RV, Galbreath EJ, Boden G, Reddy EP, Barbacid M. Loss of Cdk4 expression causes insulin-deficient diabetes and Cdk4 activation results in beta-islet cell hyperplasia. Nat Genet. 1999;22(1):44-52.

22. Ackermann J, Frutschi M, Kaloulis K, McKee $T$, Trumpp A, Beermann F. Metastasizing melanoma formation caused by expression of activated $\mathrm{N}$ RasQ61K on an INK4a-deficient background. Cancer Res. 2005;65(10):4005-11.

23. Noonan FP, Recio JA, Takayama H, Duray P, Anver MR, Rush WL, De Fabo EC, Merlino G. Neonatal sunburn and melanoma in mice. Nature. 2001; 413(6853):271-2

24. Liang X, Bhattacharya S, Bajaj G, Guha G, Wang Z, Jang HS, Leid M, Indra AK Ganguli-Indra G. Delayed cutaneous wound healing and aberrant expression of hair follicle stem cell markers in mice selectively lacking Ctip2 in epidermis. PLoS One. 2012:7(2):e29999.

25. Kobayashi T, Urabe K, Winder A, Jimenez-Cervantes C, Imokawa G, Brewington T, Solano F, Garcia-Borron JC, Hearing VJ. Tyrosinase related protein 1 (TRP1) functions as a DHICA oxidase in melanin biosynthesis. EMBO J. 1994:13(24):5818-25.

26. Waseem NH, Lane DP. Monoclonal antibody analysis of the proliferating cell nuclear antigen (PCNA). Structural conservation and the detection of a nucleolar form. J Cell Sci. 1990;96(Pt 1):121-9. 
27. Yamazaki F, Okamoto H, Matsumura Y, Tanaka K, Kunisada T, Horio T. Development of a new mouse model (xeroderma pigmentosum a-deficient, stem cell factor-transgenic) of ultraviolet B-induced melanoma. J Investigative Dermatology. 2005;125(3):521-5.

28. Hacker E, Muller HK, Irwin N, Gabrielli B, Lincoln D, Pavey S, Powell MB, Malumbres M, Barbacid M, Hayward N, et al. Spontaneous and UV radiationinduced multiple metastatic melanomas in Cdk4R24C/R24C/TPras mice. Cancer Res. 2006;66(6):2946-52.

29. DeCoster MA. Group III secreted phospholipase A2 causes apoptosis in rat primary cortical neuronal cultures. Brain Res. 2003;988(1-2):20-8.

30. Dennis LK, Vanbeek MJ, Beane Freeman LE, Smith BJ, Dawson DV, Coughlin JA. Sunburns and risk of cutaneous melanoma: does age matter? A comprehensive meta-analysis. Ann Epidemiol. 2008;18(8):614-27.

31. Bandarchi B, Ma L, Navab R, Seth A, Rasty G. From melanocyte to metastatic malignant melanoma. Dermatology Res Practice. 2010;2010

32. Du J, Miller AJ, Widlund HR, Horstmann MA, Ramaswamy S, Fisher DE. MLANA/MART1 and SILV/PMEL17/GP100 are transcriptionally regulated by MITF in melanocytes and melanoma. Am J Pathol. 2003;163(1):333-43.

33. Kucher C, Zhang PJ, Acs G, Roberts S, Xu X. Can Melan-a replace S-100 and HMB-45 in the evaluation of sentinel lymph nodes from patients with malignant melanoma. Applied immunohistochemistry \& molecular morphology : AIMM / official publication of the Society for Applied Immunohistochemistry. 2006;14(3):324-7.

34. Pisacane AM, Picciotto F, Risio M. CD31 and CD34 expression as immunohistochemical markers of endothelial transdifferentiation in human cutaneous melanoma. Cellular oncology : the official journal of the International Society for Cellular Oncology. 2007;29(1):59-66.

35. Soengas MS, Lowe SW. Apoptosis and melanoma chemoresistance Oncogene. 2003;22(20):3138-51.

36. He G, Siddik ZH, Huang Z, Wang R, Koomen J, Kobayashi R, Khokhar AR, Kuang J. Induction of p21 by p53 following DNA damage inhibits both Cdk4 and Cdk2 activities. Oncogene. 2005;24(18):2929-43.

37. Galanos P, Vougas K, Walter D, Polyzos A, Maya-Mendoza A, Haagensen EJ, Kokkalis A, Roumelioti FM, Gagos S, Tzetis M, et al. Chronic p53independent p21 expression causes genomic instability by deregulating replication licensing. Nat Cell Biol. 2016;18(7):777-89.

38. Macleod KF, Sherry N, Hannon G, Beach D, Tokino T, Kinzler K, Vogelstein B, Jacks T. p53-dependent and independent expression of p21 during cell growth, differentiation, and DNA damage. Genes Dev. 1995;9(8):935-44.

39. Ramirez JA, Guitart J, Rao MS, Diaz LK. Cyclin D1 expression in melanocytic lesions of the skin. Ann Diagn Pathol. 2005;9(4):185-8.

40. Oba J, Nakahara T, Abe T, Hagihara A, Moroi Y, Furue M. Expression of c-kit, p-ERK and cyclin D1 in malignant melanoma: an immunohistochemical study and analysis of prognostic value. J Dermatol Sci. 2011;62(2):116-23.

41. Wang H, Spillare EA, Wang QS, Sabourin CLK, Stoner GD. p53-independent down-regulation of cyclin D1 and p21Waf1 in the process of immortalization of human esophageal epithelial cells. Int J Oncol. 1998; 12(2):325-8

42. Stahl JM, Cheung M, Sharma A, Trivedi NR, Shanmugam S, Robertson GP. Loss of PTEN promotes tumor development in malignant melanoma. Cancer Res. 2003;63(11):2881-90.

43. Persad S, Attwell S, Gray V, Delcommenne M, Troussard A, Sanghera J, Dedhar S. Inhibition of integrin-linked kinase (ILK) suppresses activation of protein kinase B/Akt and induces cell cycle arrest and apoptosis of PTENmutant prostate cancer cells. Proc Natl Acad Sci U S A. 2000;97(7):3207-12.

44. Yoganathan TN, Costello P, Chen X, Jabali M, Yan J, Leung D, Zhang Z, Yee A, Dedhar S, Sanghera J. Integrin-linked kinase (ILK): a "hot" therapeutic target. Biochem Pharmacol. 2000;60(8):1115-9.

45. Widenmaier SB, Sampaio AV, Underhill TM, Mclntosh CH. Noncanonical activation of Akt/protein kinase B in \{beta\}-cells by the incretin hormone glucosedependent insulinotropic polypeptide. J Biol Chem. 2009;284(16):10764-73.

46. Mahajan K, Mahajan NP. PI3K-independent AKT activation in cancers: a treasure trove for novel therapeutics. J Cell Physiol. 2012;227(9):3178-84.

47. Sun M, Wang G, Paciga JE, Feldman RI, Yuan ZQ, Ma XL, Shelley SA, Jove R, Tsichlis PN, Nicosia SV, et al. AKT1/PKBalpha kinase is frequently elevated in human cancers and its constitutive activation is required for oncogenic transformation in NIH3T3 cells. Am J Pathol. 2001;159(2):431-7.

48. Geng Y, Walls KC, Ghosh AP, Akhtar RS, Klocke BJ, Roth KA. Cytoplasmic p53 and activated Bax regulate p53-dependent, transcription-independent neural precursor cell apoptosis. J histochemistry and cytochemistry : Official J Histochemistry Society. 2010;58(3):265-75.
49. Benchimol S. p53-dependent pathways of apoptosis. Cell Death Differ. 2001;8(11):1049-51.

50. Yerlikaya A, Okur E, Ulukaya E. The p53-independent induction of apoptosis in breast cancer cells in response to proteasome inhibitor bortezomib. Tumour biology : J Int Society Oncodevelopmental Biology Medicine. 2012:33(5):1385-92.

51. Degenhardt K, Chen G, Lindsten T, White E. BAX and BAK mediate p53independent suppression of tumorigenesis. Cancer Cell. 2002;2(3):193-203.

52. Schrama D, Keller G, Houben R, Ziegler CG, Vetter-Kauczok CS, Ugurel S, Becker JC. BRAFV600E mutations in malignant melanoma are associated with increased expressions of BAALC. J Carcinogenesis. 2008;7:1.

\section{Submit your next manuscript to BioMed Central and we will help you at every step:}

- We accept pre-submission inquiries

- Our selector tool helps you to find the most relevant journal

- We provide round the clock customer support

- Convenient online submission

- Thorough peer review

- Inclusion in PubMed and all major indexing services

- Maximum visibility for your research

Submit your manuscript at www.biomedcentral.com/submit
Biomed Central 